\title{
Patients and their medical records: It is time to embrace transparency
}

\author{
Kirsten Patrick MBBCh DA
}

I don't have direct access to my medical record, although I could ask to see it under Ontario's Personal Health Information Protection Act. ${ }^{1}$ My physician is obliged to let me see my medical record, barring a few specific circumstances, and is required to grant me access to it within 60 days, although in some regions 90 days "is permissible" (really?). For access, I would almost certainly be charged a fee. The situation is similar in other jurisdictions: legal rights with hoops and speed bumps.

Why would I want to view or ask to amend my medical record? After all, it is (currently) pretty thin. I've lived in Canada for only a year, and I've visited my family doctor only twice. Well, that's entirely the point. I'd like to make sure that all the information that is relevant is there. Many patients move cities, provinces or countries, and gather a patchy medical record over a lifetime. Physicians have a duty to ensure that medical records are accurate and complete. Although physicians may interpret this as extending only to their own notes, a medical record with substantial gaps may result in a patient receiving suboptimal care, which is not in the best interest of either the patient or the physician. There are other arguments for allowing patients easy access to their medical records, not the least of which is that patients Really Like It.

Patient access to health records has been piloted successfully, and apparently without system collapse, both in secondary care services and primary care practices. One of the largest of these studies $^{2}$ trialled open notes across three primary care practices in three US states for a year. Afterward, $99 \%$ of patients wanted open notes to continue beyond the experiment, and no doctor chose to stop. That's telling. The vast majority of patients surveyed across studies reported feeling more in control of their care and more likely to adhere to medication when they could access their notes. The burden on physicians appeared to be minimal, and no adverse events were reported.

There are important concerns. Security is always a concern, but patient identification details for medical records could be protected just as well as banking, pension, tax and insurance details are, by using the same mechanisms. A minority of patients find reading their medical notes confusing or offensive. This speaks to the need for physicians to be respectful in written notes and to take the time to explain the language they use to patients. Some patients admit to sharing their record with another person. As in other domains, we must educate patients about what information is appropriate to share.

Interestingly, the majority of patients would like to have the right to "approve" or "amend" their records. Physicians strongly oppose this idea; they know that the legal obligation to maintain an accurate medical record and not to "doctor" it, rests with the physician. Allowing patients the ability to "leave a comment" or change address details would be feasible, but allowing patients unfettered access to records is not feasible, given the illegality of erasing or falsifying a part of the medical record such as a history of depression or the termination of a pregnancy.

Now used in over $70 \%$ of primary care practices in Canada, electronic health records are unquestionably better than paper records, albeit that electronic records are plagued with problems. Yet, designed with the needs of health care systems and providers in mind, electronic health records are no more transparent to patients. Why? Is sharing the entirety of the electronic medical record with a patient not the obvious next step in the laudable movement toward shared decision-making and patient-physician collaboration, an ideology that is well established in Canadian health care?

Many physicians $d o$ already share the contents of their notes with patients openly and willingly, if informally. Some physicians choose to turn the computer screen to the patient as they type and to dictate referral letters in the presence of a patient, believing that they should not be writing anything about a patient that they would not want him or her to read. Modern information technology and Internet capability offer the potential for useful transparency that has been shown to benefit patients and the health care system. It is no longer appropriate for physicians to want to conceal their version of a patient's story from the patient. Proper shared decisionmaking depends on a story on which both agree. Physician and patient groups in Canada must work together with creators of medical information technology to find solutions that will allow electronic medical records to be safely transparent to patients while protecting health care staff from becoming overburdened. A failure by physicians to take a lead on this will mean that they may become victims of pressure or legislation.

\section{References}

1. Personal Health Information Protection Act, 2004. Available: www.e-laws.gov. on.ca/html/statutes/english/elaws_statutes_04p03_e.htm\#BK65 (accessed 2014 June 24).

2. Delbanco T, Walker J, Bell SK, et al. Inviting patients to read their doctors' notes: a quasi-experimental study and a look ahead. Ann Intern Med 2012;157:461-70.

Competing interests: See www.cmaj.ca/site/misc/cmaj_staff.xhtml

Affiliation: Kirsten Patrick is Deputy Editor, CMAJ

Correspondence to: $C M A J$ editor, pubs@cmaj.ca

CMAJ 2014. DOI:10.1503/cmaj.140834 